\title{
Development Trend of Mobile Blended Learning for College Students in the Industrial Industries Context of Big Data
}

\author{
Cizhen Zhang \\ School of Educational Science, Xiang'nan University, Chenzhou, Hunan, China
}

\begin{abstract}
The advent of the web2.0 era has prompted big data in education to integrate many high-quality online course resources, providing a good platform for college students to carry out mobile learning and blended learning. The rapid development of mobile learning has changed it from an auxiliary and optional learning mode to an available and inseparable learning mode. During the epidemic period, mobile online learning mode has shown diversified characteristics with a wide range of learning platforms. As a new learning mode, mobile blended learning has been accepted and used by more and more learners and has become an important development direction of higher education in China and the world.
\end{abstract}

Keywords: Industrial Big Data, big data platform, university man, mobile learning, blended learning

\section{Introduction}

With the rapid development of industrial industry, the advent of the web2.0 era has prompted big data in education to integrate many high-quality online course resources, providing a good platform for college students to carry out mobile learning and blended learning. The rapid development of mobile learning has changed it from an auxiliary and optional learning mode to an available and inseparable learning mode. During the epidemic period, mobile online learning mode has shown diversified characteristics with a wide range of learning platforms. As a new learning mode, mobile blended learning has been accepted and used by more and more learners and has become an important development direction of higher education in China and the world.

\section{Education Reform in the Context of Big Data}

Big data (mega data) refers to a large, high-growth and diverse information asset that requires a new processing model to have greater decision-making power, insight, and process optimization capabilities. The rapid development of information technology has made the full coverage of big data an indispensable valuable asset in this network era. The integration of big data and education is the inevitable requirement of the development of the times and the combination of information technology and traditional classroom teaching. In this way, its educational model, teaching evaluation, teaching research and learning methods all have a "new paradigm". ${ }^{[1]}$

The education big data platform provides rich and high-quality education and teaching resources, which can not only share high-quality learning resources for students from different regions and different levels, solve the problem of uneven distribution of educational resources, but also find a platform to meet their own development and personalized teaching and learning needs. With the continuous in-depth development of MOOC, there are more and more online high-quality video course resources, such as icourse MOOC, Netease Open Class, Sina Open Class, xuetang X, Khan Academy, as well as video courses such as video open class and resource sharing class developed and established by various universities, which are not only free but also of high quality, can be accessed anytime and anywhere by using wireless network through tablet computers and smart phones, and are high-quality resources for college students to carry out mobile learning and blended learning.

So far, the icourse MOOC platform has more than 8,000 operating courses, including 916 national excellent online open courses, which cover all major categories of 12 undergraduate courses and 18 major categories of higher

ISSN: 0010-8189 
vocational education. Among these courses, 3,915 courses are offered by 121 double first-class universities, and more than 130 courses are offered in the first-class university construction series, the first-class discipline construction university series, the industry characteristic university series, and the characteristic special subject series, with more than 30 million registered users and more than 140 million people studying. Since the official launch of xuetangX on October 10, 2013, there are courses from first-class universities at home and abroad such as Tsinghua University, Peking University, Fudan University, China University of Science and Technology, as well as Massachusetts Institute of Technology, Stanford University and the University of California at Berkeley, covering 13 major disciplines, totaling over 3,000 high-quality courses.

In traditional classroom teaching, attention is paid to imparting classroom knowledge, but individual differences and timely feedback are neglected. In contrast, big data in education has changed the way students learn, making learning on each network teaching platform can be recorded at any time and timely feedback, which has also caused the rise of a variety of new teaching methods, such as flipped classroom, cooperative inquiry teaching, and blended teaching, and promoted a new wave of educational change.

\section{Current Situation of Mobile Learning of College Students}

Mobile learning refers to learning activities that learners use the network and mobile devices (e.g. smartphones, tablets, laptops, Kindle and other e-book readers) to obtain learning resources or carry out on-demand learning activities anytime and anywhere through service platforms, which provide strong support for learners' autonomous learning. It is developed on the basis of e-learning, which is an extension of e-learning, different from general learning, and is considered as a future learning mode, or an indispensable learning mode for future learning, characterized by mobility, fragmentation, timeliness, interactivity, context, autonomy, efficiency and lifelong learning, as shown in Fig. 1 below. ${ }^{[2]}$

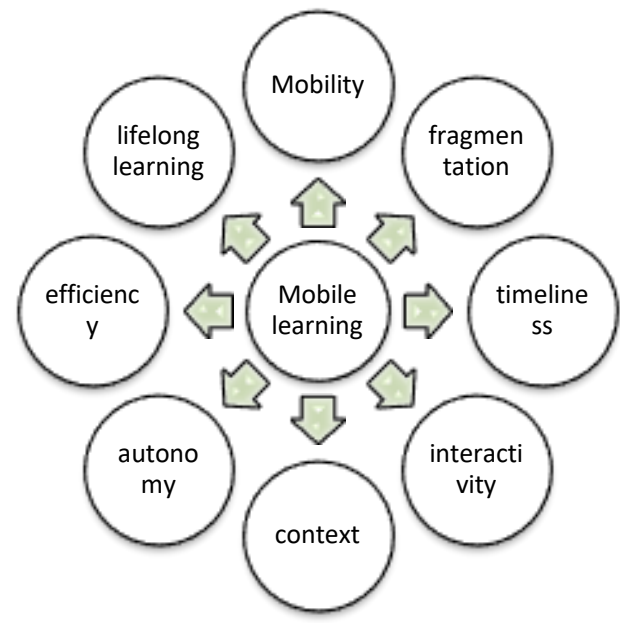

Fig. 1 Features of mobile learning

Studies have shown that global mobile data traffic grew three times faster than desktop traffic from 2014 to 2019. With the development of $4 \mathrm{G}$ and $5 \mathrm{G}$ mobile communication technology, the technological innovation and low price of intelligent mobile terminals, and the endless emergence of mobile APP, the position of mobile learning in China's education has been gradually recognized, and college students are relying more and more on smart phones for socializing, entertainment and learning. Mobile learning after continuous development has become an indispensable from an optional way of learning, which is developing better and faster in colleges and universities. It will also be a part of online learning in blended learning, and can participate in learning at any time, feedback and participate in the learning process in time.

According to a study of China Education and Science Computer Network, the prediction of mobile learning trends

ISSN: 0010-8189 
in 2019 shows the following ten trends: According to a study by China Education and Science Computer Network, the prediction of mobile learning trends in 2019 shows the following ten trends: (1) Bring your own equipment; (2) Mobile priority design plays an increasingly important role in the development of learning content; (3) With the rapid rise of mobile applications, more and more companies use mobile learning to conduct training; (4) Video content is dominated, supplemented by voice interaction; (5) Gamification is widely adopted; (6) Location-based technology, artificial intelligence and machine learning bring a better personalized experience; (7) Offline learning becomes a part of online learning; (8) Mobile micro-test is emerging to help consolidate knowledge; (9) Mobile guidance will become an essential item for employee training; (10) Augmented reality and virtual reality make the performance support function of mobile learning stronger. ${ }^{[3]}$

Therefore, the online learning mode of colleges and universities at home and abroad is constantly developing towards mobile learning which is characterized by intelligence, fragmentation and autonomy, especially in the digital learning terminal in the blended learning mode. With the popularization and development of mobile learning platform in colleges and universities, more and more colleges and universities pay attention to the platform function to the actual teaching effect, which indicates that the mobile learning platform has entered the era of big data. According to statistics, nearly $47 \%$ of organizations around the world are using mobile learning, which is increasing rapidly and has become the future trend of learning.

\section{Development of Mobile Learning among College Students during the Epidemic}

Under the impact of the COVID-19 outbreak, in order to ensure students' learning, the policy of "suspended classes without stopping school" has been favored by schools, students and parents all over the world. As a result, computers, smartphones and tablet computers have become teaching and learning tools, and mobile learning methods are being carried out in full swing all over the country. College students make full use of large data learning resources to help their professional learning.

According to the statistics released by China Internet Network Information Center (CNNIC) on April 28, the number of Internet users in China has reached 904 million by March 2020, which has maintained a steady growth trend compared with the end of 2018 and June 2019. ${ }^{[4]}$

In terms of teaching, offline teaching was suspended one after another during the epidemic, which strengthened the dependence of netizens on online education platform. Although the number of users was lower than usual due to winter vacation, it increased by $22 \%$ compared with last year's Spring Festival, with the duration increased by $30 \%$.

The growth of mobile blended learning during the epidemic period

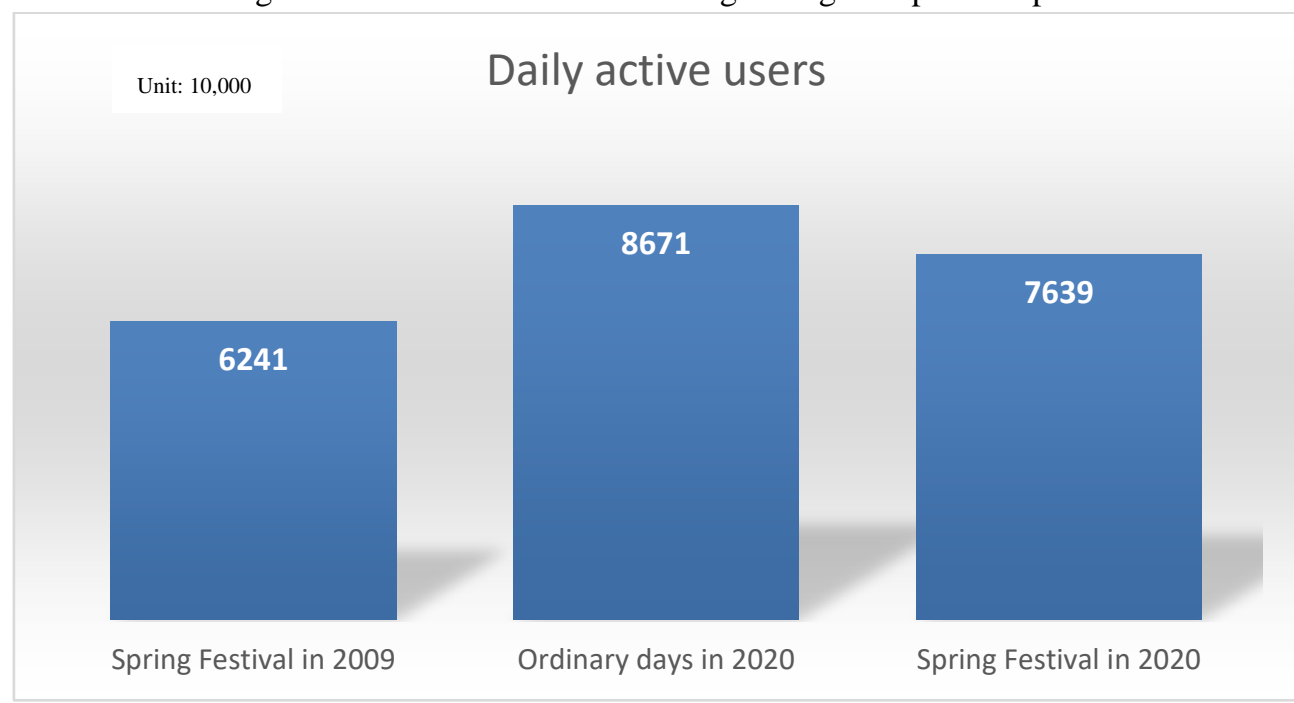

ISSN: 0010-8189 
Fig. 2 Daily active users nearly two years

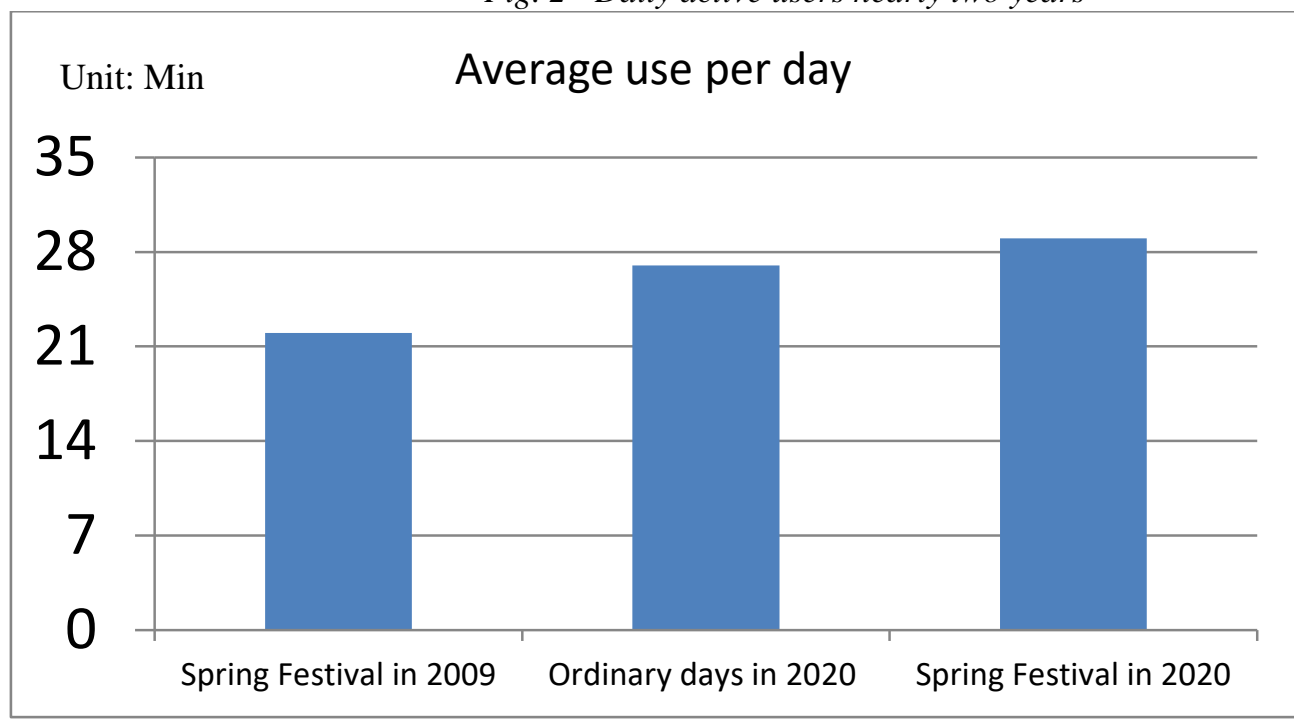

Fig. 3 Average use per day nearly two years

According to the survey of online teaching conducted by Xiamen University Teacher Development Center, nearly $60 \%$ of the students did not take online teaching before the epidemic, among which 51,674 students had online teaching before the epidemic, accounting for 44\%, 66,517 students had no online teaching before the epidemic, accounting for $56 \%$, and $97 \%$ students used online teaching during the epidemic. ${ }^{[5]}$

During the epidemic period, the way of mobile learning is more and more popular with college students, which provides beneficial assistance for the study of college courses and constantly changes their learning habits. In addition, teachers use new information-based teaching methods to construct their own courses or make use of existing high-quality resources in the actual teaching process. The most frequently used teaching and learning apps are Chaoxing, icourse MOOC, xuetangX, CNMOOC, Zhihuishu, Netease Cloud Class, Moso Teach, Rain Classroom, WeChat Public Platform, etc., indicating that the new information-based teaching model is gradually advancing. Up to now, more than 550,000 courses have been newly constructed by teachers across the country on the Chaoxing platform, and nearly 10 million users are teaching online at the same time, which is dozens of times higher than usual. With the massive and high-quality courses provided by icourse MOOC and Netease Cloud Classroom, users can arrange their own learning progress according to their own learning level.

In terms of online education platforms, the education and learning APP gained momentum after the Spring Festival. After being notified of the extension of the winter vacation, typical platforms opened free courses one after another to ensure "continued learning". According to statistics, the top five apps with active users in education and learning app industry in 2020 before and after the Spring Festival holiday are: xuexi.cn, zuoyebang, Youdao Dict webpage, yuansouti, TAL Education Group and yuanfudao. For example, xuexi.cn that ranked the first had received more than 16 million hits per day for its high-quality free courses launched on the APP from January 14 to February 4 , 2020, 20.149 million hits on February 4, followed by free live lessons in zuoyebang, which rose from 4 million during the Spring Festival to more than 14 million ten days later. ${ }^{[6]}$

Characteristics of online learning among college students during epidemic period;

\subsection{Diversified online learning models}

Compared with the traditional classroom learning in the past, the online learning mode of college students during the epidemic was diversified characteristics, in the forms of live streaming online, video conference, recorded broadcast, MOOC, SPOC, PPT recording, etc. The first method is live streaming and video conference, which is 
basically the same as offline classroom teaching mode, in which teachers give lectures on knowledge points in live streaming software such as QQ live streaming, Tencent classroom, Tencent conference or Ding Talk, etc. students listen to lectures using terminals such as mobile phone APP and computer, and at the same time can ask questions in the discussion section, or ask questions or answer questions from teachers, which requires a smooth network. However, many students reflect that there will be lost connections, and some software cannot support playback, which will affect the learning effect. The second method is for the students to preview and complete the related discussion in advance, then the teacher will sort out the knowledge points, explain the important and difficult points and answer questions interactively through live streaming, and finally the students will complete the related exercises., which is equivalent to the flipped classroom so that the students can learn to participate in the discussion and complete the exercises first. The third way is for students to use online courses or recording and broadcasting courses for self-study, so that students can learn independently according to the learning materials (teaching materials, PPT, recorded broadcast, videos, etc.) issued by the teachers or on the corresponding online course platforms (such as MOOC and Chaoxing), and complete the corresponding tests, discussions, etc. as required. Among these three methods, the proportion of teaching by live streaming is the largest, followed by providing materials for self-study, and some teachers and students will have several live classes on the basis of self-study. According to the author's investigation, most college students like self-regulated learning, because they are not limited by the speed and time and place of the network, and can make their own arrangements.

\subsection{Increased proportion of self-regulated learning}

From the perspective of learning mode, although a few courses still copy the offline learning mode, the proportion of students' self-regulated learning has been increased more or less in most professional courses, especially in the part of homework in order to test the learning effect of students, and most students think that the learning task is several times heavier than that in school. According to the survey, nearly $70 \%$ of students think that homework assignments are more frequent. In addition, from the perspective of the curriculum links of the mainstream learning model, apart from daily live online learning, classroom tests and homework, in most courses, pre-class preparation, learning experience, feedback of difficult points, group discussion and turning over the classroom are added to the online learning platform as part of the course performance assessment, and some students do not pay attention to them, resulting in a widening learning gap.

\subsection{Many and diverse learning platforms}

Different courses are offered on different learning platforms, and some different platforms or software will be used in multiple learning links of the same course. The number of teaching platforms used in each course varies from 1 to 10 , which requires students to know the teaching arrangements of various subjects in advance, skillfully switch platforms or software to learn, and always pay attention to the notifications, assignments and tests of various platforms, so as not to miss the punch-in, assignment submission and curriculum adjustment messages, inevitably increasing students' learning pressure.

Online learning during the epidemic period not only includes mobile learning mode, live streaming+ offline blended learning mode, but also can be played back repeatedly, which is convenient for reviewing and consolidating knowledge, breaks through time and space constraints, ensuring learning at any time and place. By using the education big data platform, classes of famous teachers can be fully shared, and students' autonomous learning ability and collaboration ability are cultivated. The biggest challenge of online learning for students is to have certain autonomous learning ability and good online learning behavior habits. Another important factor that affects online learning effect is the improvement and stability of network speed and teaching platform function.

According to the author's survey of college students who adopted online teaching this semester, regarding their acceptance of online teaching after the epidemic, more than $50 \%$ of the students indicated that they accepted the online+ offline mixed teaching method, and they would continue to adopt online learning while taking lectures in class, thus forming a good learning habit and improving their autonomous learning ability.

ISSN: 0010-8189 
Online teaching has brought four changes: first, the learning scene has changed from a face-to-face classroom to a remote network environment; second, the teaching interaction mode has changed from "face-to-face" to "teacher-machine-student", and the interaction between teachers and students has been strengthened; third, the status of teachers and students has changed from teacher-centered to student-centered, and the autonomy of learning has been greatly improved; fourth, the role of technology has changed from an important support to an essential teaching element as important as teachers, students and teaching content, and the accuracy of teaching management in schools has been further improved.

The epidemic has also brought people three conveniences. First, high-quality resources are shared. A large number of famous teachers and schools, including high-quality social resources, are free and open to all teachers and students. Second, teachers are coordinated. Teachers who were originally based on the units of schools and classes have the opportunity to be re-coordinated throughout the country, thus creating a value-added effect. Third, the construction level of educational information infrastructure has been significantly improved, laying the foundation for the normalized application of large-scale online teaching.

\section{Conclusions}

As Wu Yan, Director of the Department of Higher Education of the Ministry of Education, said at the press conference held by the Ministry of Education on May 14, in the future, we should make full use of the "learning revolution" set off during the epidemic to solidly promote the online teaching practice of "quality revolution" in higher education personnel training. After the resumption of classes, online education should also be changed from "novelty" to "new normal". We can't and shouldn't return to the state of teaching and learning before the outbreak, because online teaching with "internet plus" and "smart+"technology has become an important development direction of higher education in China and the world. ${ }^{[7]}$

\section{Acknowledgements}

This paper was financially supported by Teaching Reform Research Program of Hunan Universities Practice of Blending Teaching in Universities Based on Smart Classroom, X.J.T. [2019] No. 291, Project No.: 896; Social Science Planning Subject of Chenzhou City Construction and Application of Education Informatization in Local Institutions (Czssk12018065).

\section{References}

[1] G. H. Liu, Y. Mei, Overview of Development of Big Data in Education, China Modern Educational Equipment, 2020 (6): 18-21.

[2] S. X. Qi, Investigation and Promotion Strategies of Mobile Learning of Higher Vocational College Students Based on the Case Study of Kindergarten Teachers and Students of a Higher Vocational College. Guangxi Normal University, 2019.

[3] Top Ten Trends of Mobile Learning $\quad$ in 2019. http://www.edu.cn/xxh/media/yjfz/yjbg/201905/t20190528_1660638.shtml

[4] Internet User Behavior during the Epidemic. https://zhuanlan.zhihu.com/p/136116728.

[5] Investigation Report on Online Learning of Undergraduates during the Epidemic. https://www.sohu.com/a/389414708_115563

[6] Mobile Internet reports during the outbreak issued by Quest Mobile. https://www.ruancan.com/news/quest-mobile-releases-mobile-internet-report-during-epidemic.html

[7] Ministry of Education: Online teaching should change from "freshness" to "new normal". http://www.xinhuanet.com/2020-05/15/c_1125986698.html. 